

\author{
LA JOLLA, CALIFORNIA
}




Digitized by the Internet Archive in 2008 with funding from Microsoft Corporation 





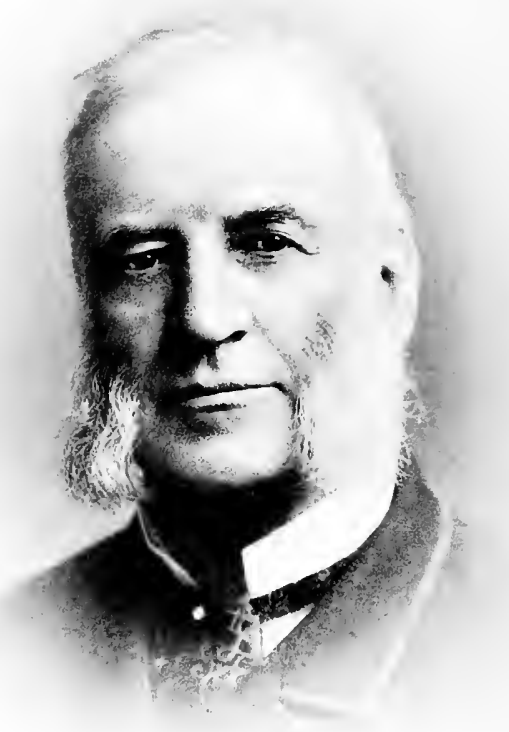

$$
\text { Austiv forit. }
$$




\title{
MEDICINE OF THE FUTURE
}

AN ADDRESS PREPARED FOR THE ANNUAL MEETING OF THE BRITISH MEDICAL ASSOCIATION IN I886

BY

AUSTIN FLIN'T (Senior), M.D., LL. D.

\author{
NEW YORK \\ D. APPLETON AND COMPANY \\ I, 3, AND 5 BOND STREET \\ 1886
}


Copyright, 1886,

BY D. APPLETON AND COMPANY. 
The late DR. AUSTIN FLINT was appointed to read the address on Medicine before the Britis/ Medical Association at its meeting in I886. The manuscript was found anong his papers and the address is printed preciscly as it was written. The proof was reverently read by his son, who dedicates this, his father's last litcrary work, to the profession he so loved and adorned.

AUSTIN FLINT.

April 24, 1886. 



\section{MEDICINE OF THE FUTURE.}

THE meditations of a medical practitioner whose retrospections extend over half a century may naturally be expected to revert to the past. To review the progress of medicine for fifty years, to make comparisons of the beginning and the end of that period, to revive the enthusiasm of by-gone days-these are among the resources of those who may be called medical semi-centenarians. In the ability to look backward through so long a period, is to be found some compensation for deprivations incident to the passage of one's life beyond youth and middle age. Retrospection has uses apart from this compensatory gratification; but, if too absorbing, it impairs appreciation of the present and faith in the future. To look forward, as well as backward, is both interesting and useful. If our retrospections extend over half a century, it is worth while to inquire, How will the present appear in a retrospective view at the end of the next 
fifty years? In the spirit of this inquiry, I shall submit some thoughts on medicine of the future.

I assume that medicine, as it is to-day, will not remain stationary. In everything relating to human knowledge, anticipations have no basis other than experience. The past history of medicine shows a law of progress; hence, medicine will continue to advance. I shall view this conclusion, however, from another and a higher standpoint. If we believe in an overruling Creator and Governor of the universe, everything, however great or however small, must be in accordance with a divinely ordered plan. Diseases doubtless have their uses, some of which are apparent to human comprehension. The prevention and the successful management of diseases also enter into providential design. The past gives an assurance of progressively increasing security of human life from diseases. The progress of medicine belongs, therefore, in the order of Providence.

Past experience shows that medicine advances by means of discoveries and improvements which mark epochs in its history. Immediately preceding the beginning of the last half-century, following the discovery of vaccination, by Jenner, and the developments in anatomy, physiology, and pathology, by the researches of John Hunter, were the 
discovery of auscultation by Laennec, the inauguration of renal pathology by Richard Bright, the creation of general anatomy by Bichat, and the advancement in knowledge of the nervous system by the experiments of Magendie and Charles Bell. These were epochs occurring in quick succession. The epochs within the last half-century have been as many, as important, and as rapid as during the previous fifty years. They whose retrospections embrace this period of time can recall the discovery of the reflex system of nerves, and of the separate functions of different portions of the spinal cord; the study of diseases after the numerical method; the recognition of the self-limitation of certain diseases and knowledge of their natural history; the creation of histology, by means of the microscope ; the localization of certain of the cerebral functions ; the employment of anæsthetics and their applications in medicine as well as in surgery and obstetrics; the clinical introduction of the ophthalmoscope and the laryngoscope; the clinical use of the thermometer; and, as a crowning epoch, the more recent revelations respecting the bacterial origin of diseases. Now, suppose that whoever may be honored by an invitation to read an address on medicine at the annual meeting of the British Medical Association in the ycar 1936 should select 
as his theme the history of medicine for the preceding half-century, is it to be doubted that the epochs belonging to this history will be found to te not less in number and in importance than those which signalized medical progress during the first half of the century ending at that date? Does not the history of medicine show a steady acceleration in progress, so that, judging by the past, these next fifty years will be richer in epochs than the previous half-century? *

Has our knowledge of the organs, tissues, and chemical constituents of the body reached its limitations? About half a century ago, Horner, of Philadelphia, described a lachrymal muscle, which bears his name, measuring three lines in breadth and six lines in length. At that time this little muscle seemed the only thing left for discovery in macroscopical anatomy. But soon afterward, a new continent in this department of medicine was discovered, and the question now is, How much further can future exploration in microscopical

* Sir James Paget, in his inaugural address at the opening of the International Medical Congress in I 881 , expressed his belief that the progress of science " in the last fifty years was twice as great as that in the previous fifty," and that "the rate of progress should constantly increase." If the latter belief be in accordance with the order of Providence, how interesting will be the retrospections of half a century in 1936 ! 
anatomy be extended? To particularize the epochs to take place in the future would be equivalent to making them; but conjecture respecting the means by which they are to be made is admissible. It is probable that the construction of the microscope admits of continued improvements. The illumination of microscopical objects may be increased. The practical applications of the spectroscope may be enlarged. The developments in optics may furnish new methods of observation. The process of staining, which has recently done so much for pathology, may be extended and applied to the study of the normal as well as morbid components of the body. It is a fact, significant as regards the future, that the use of dyes has brought into the range of vision objects which, without their use, the microscope fails to make visible.

Analytical chemistry carries investigation beyond the limits of microscopical observation. The latter, at the present moment, both in pathology and physiology, seems to promise most; but is it not a rational anticipation to look for future results from chemical analysis of the components of the body, in health and disease, which in brilliancy and practical utility may surpass those of the labors in this field of investigation during the past halfcentury? The medical semi-centenarian can recall 
the enthusiasm aroused by the labors of Liebig. Histology is now in the ascendant, but it is safe to predict that, before the lapse of another halfcentury, there will be another era in organic chemistry, and that light will penetrate dark recesses which histology can not reach. Tracing to protoplasmic cells physiological and pathological processes brings us in close proximity to these processes, but they are not thereby elucidated. Histology may disclose the agents, but it leaves us in the dark as regards the agencies. How is it that secretions, excretions, nutrition, growth, and certain morbid products are brought about? This question can not be answered with our existing knowledge, and the answer must come from organic chemistry. The supreme objects of study in pathology at the present time are the discovery of micro-organisms and their natural history. But these agents, it is probable, are pathogenetic, not directly, but indirectly, by means of the toxical products of their activity. What are these products, and how do they give rise to the phenomena of disease? We may ask the same question of certain of the poisons introduced from without the body. How is it that fractional quantities of morphia, hyoscyamin, strychnia, aconitia, atropia, and other alkaloids, produce their lethal effects? It 
conveys no adequate information to say that they act upon the nervous system. This is merely the statement of a fact, not an explanation. For the latter, we must look to the organic chemistry of the future.

The progress of medicine, so far as it depends on observation, has been effected especially by the sense of sight. The sense of hearing, it is true, has contributed most important information, especially respecting the organs within the chest. It is needless to refer to the knowledge obtained by means of auscultation and percussion of the lungs and heart. A large share of this knowledge has been obtained within the last half-century. It is needless, also, to refer to the marvelous developments, within the last few years, of knowledge respecting the transmission of sounds outside of the body, as exemplified by the telegraph, the telephone, the microphone, and the phonograph. These developments have not as yet added much to our knowledge of the normal and abnormal actions taking place within the body. Much is to be expected from this source in the future. It seems to me certain that the principle of the telephone will, by-andby, be applied to intra-thoracic respiratory and heart-sounds, so that they will be transmitted to the ear with more distinctness than they now 
are by the binaural stethoscope. The healthy and morbid sounds will then be so easily observed as to render the physical diagnosis of pulmonary affections in all cases a very simple problem. More than this, the clinical teacher may be able to demonstrate auscultatory signs to a class of medical students comfortably seated in the lecture-room or hospital amphitheatre. The same is to be said of auscultation of the heart. The cardiac murmurs and the sound produced by each of the valves of the heart separately, will be observed more readily and satisfactorily than with our present means of observation. I will go further, and say that intrathoracic sounds may be transmitted from the patient to the physician, no matter how distant may be the one from the other. Again, and still further, the sounds from the chest of a patient may be phonographically registered, transported never so far, and made available after an indefinite period. All these results would not be more wonderful than the invention of the telegraph, the telephone, the microphone, and the phonograph, all of which have been devised within the last half-century.

I may mention an incident, an account of which I recently read in a newspaper, illustrative of a practical use of the telephone in diagnosis. A telephonic communication existed between the house 
of a physician and the distant residence of a patient. The physician was summoned to visit a child in the house of the patient in the night-time. The physician naturally asked, "What is the matter?" The answer was that a child had croup. Said the physician, "Bring the child close to the telephone that I may listen to the cough." This was done. The cough was heard, and the physician telephoned his opinion and instructions, without the necessity of making a night-visit. A description of the symptoms in certain cases, transmitted by means of the telephone, may not infrequently spare both the physician and the patient the inconvenience of a journey either in the night or day time. How far it may be for the interest of the physician to make use of the telephone in this way, depends on circumstances, the consideration of which is not especially suited to this occasion.

In 1705, Robert Hook, who, as we are told, "was for many years a prime mover in English science-mathematician, physicist, chemist, engineer, microscopist, physiologist, virtuoso, and city surveyor-a man of almost unbounded fertility and vast energy," uttered this prophetic exclamation: "Who knows but that one may discover the works performed in the several offices and shops of a man's body by the sounds they make, and thereby dis- 
cover what instrument or engine is out of order!"* Were Hook now living, he might claim that his prophecy has been fulfilled by the developments in auscultation of the respiratory organs and the heart. Moreover, auscultation has developed signs in addition to those relating to the voice, the respiration, and cardiac sounds. Fifty years ago, Fisher, of Boston, found, on applying the stethoscope over the fontanelles in infants, a bellows-murmur in cases of cerebral diseases. Another of my countrymen, Hooker, of New Haven, studied the intestinal borborygmi in cases of colic. Murmurs in the arteries and veins, and in the several varieties of aneurisms, as is well known, afford important information. Pregnancy and the prospect of twins may be ascertained by listening to the sounds of the fœtal heart. A collection of gall-stones is sometimes made known by the noise they make, and hydatids have been recognized by a musical tone. But the fulfillment of Hook's prophecy is not yet complete. At the present day, we may say, Who knows but that, with improvements in instruments for the conduction and intensification of sounds, one may study normal and abnormal conditions of the circulation in all the internal organs of the body, "by the sounds

* “Inaugural Address," by Dr. Michael Foster, Presidént of the Section on Physiology, at the International Medical Congress of $188 \mathrm{r}$. 
they make" in the processes of secretion and excretion, of nutrition and of morbid growths? It can hardly seem an extravagance to predict, then, of the future developments of auscultation to one who has listened, with the aid of the microphone, to the footsteps of a fly.

A half-century ago, the profession had acquired but imperfect knowledge of the natural history of diseases-that is, the history of diseases pursuing their course unaffected by active measures of treatment. The importance of this knowledge was not fully appreciated. Diseases which we now know to be self-limited in duration, and to tend intrinsically to recovery, were treated as if their continuance were indefinite and their course interminable, irrespective of active therapeutic measures. The influence on therapeutics of the knowledge of the natural history of diseases, acquired within the last fifty years, has been great. It is evident that this knowledge is the true point of departure for estimating the effect of treatment, and that without this knowledge the conclusions derived from clinical experience must often be erroneous. There is still room for the increase of this knowledge, and in this direction we are to look for further influence on therapeutics. With the now prevailing views, it seems a surprising statement that phthisis 
pulmonalis may be self-limited and end in recovery purely from an intrinsic tendency; yet, I venture the assertion that the correctness of the statement has been substantiated, and that before many years elapse it will be generally acknowledged to be a clinical fact. How important is this fact in judging of the agency of medicinal, climatic, and hygienic measures in the treatment of this disease!

Assuming, as we must, that the only solid basis of therapeutics is clinical experience, and appreciating the many and almost insuperable difficulties in the way of educing therefrom conclusions which approximate to the "inflexibility of arithmetic," it is an interesting inquiry, What will be the status of the therapeutical principles which have heretofore governed and of those which now govern the practice of medicine? The medical semi-centenarian has lived through radical changes in medical practice, especially as regards inflammatory affections. The so-called antiphlogistic measures-blood-letting, general and local, mercurialization, active counter-irritation, emetics and cathartics, conjoined with starvation diet, which, fifty years ago, were considered as indicated whenever and wherever inflammation was supposed to exist-have of late years been practically repudiated. Formerly the physician who failed to employ them would have 
been considered culpable. The physician who should now resort to antiphlogistic measures, as they were formerly employed, could not expect to escape with simply the charge of fogyism; his practice woúld be open to censure. Now, was the practice in former days altogether wrong, and is the practice of the present time altogether right? I shall apply this question to the most potential antiphlogistic measure, namely, blood-letting, with the understanding that my remarks are, to a greater or less extent, applicable to the other so-called antiphlogistic measures.

On an occasion which had called together a considerable number of medical practitioners, the question being raised how many lancets could be at the instant exhibited, it so happened that not one of those present had a lancet in his pocket. None had recognized the liability to an emergency which might call for prompt venesection. This occurrence was on the other side of the Atlantic; but it would certainly not be fair to infer that the same thing could happen at an assemblage of British practitioners. However that may be, there is not much risk in hazarding a prediction that, long before the expiration of the next half-century, no practitioner of medicine will be without a lancet at hand for immediate use. There will then be no 
longer pertinency in the title of a paper written but a few years since by my lamented friend, the late Professor Gross, in reference to venesection, namely, "A Lost Art in Surgery."

I shall not undertake to sustain this prediction by a comparison of past with present experience, collecting data from medical literature, or by rational considerations. I shall adopt a shorter but not less conclusive argument. Blood-letting for a long period entered largely into the practice of medicine. It commended itself to practitioners of sound judgment and large experience, who were good observers. Were they altogether deceived? Is it, I shall not say probable, but possible, that physicians in the early part of the last half-century, and for previous centuries, persisted in a measure of treatment which never did good, but always did harm? These questions involve that argument. Blood-letting must have been productive of more or less benefit, albeit it is potential for harm as well as good.

A fair conclusion is that, by the abandonment of blood-letting, a useful measure of treatment was given up. It was doubtless employed too indiscriminately and often carried too far. Its dangers and evils were as much overlooked as they are now exaggerated. Its use was not properly regulated 
by indications and contra-indications. The time will come (and that ere long, for it is now foreshadowed) when it will have its proper rank among therapeutic agencies. Physicians will take advantage of the promptness and efficiency of its effect in certain conditions of disease, and will observe a proper conservatism as regards its potency for harm as well as good. To carry out the principle of rejecting remedies because they are capable, if used without due discrimination and discretion, of doing harm, would be to emasculate the materia medica. A remedial agent can have but little value if it be not capable of acting injuriously as well as usefully. In the ability to employ potential agencies so judiciously as to secure their good and avoid their evil effects, lies the secret of true success in the practice of medicine.

I come now to an event in the progress of medicine, already adverted to and characterized as the crowning epoch in the medical history of the last half-century. I refer to bacterial etiology. My own impressions, in respect to the interest and importance of this topic, are such that my remarks will perhaps be considered as illustrative of that tendency to exaggeration and extravagance of utterance which is one of the peculiarities of the American people. We are entering upon a revolution in 
medicine. It is bewildering to project the thoughts into the future in order to foresee changes which will be brought about, in the coming half-century, in our knowledge of the causation of diseases and the results as regards their prevention and treatment.

The candid reader of medical history can not but be impressed with the lack of accurate information of the causes of disease. In morbid anatomy, macroscopical and microscopical, in symptomatology and clinical description, in differential diagnosis, and in knowledge of the causative connection with each other of different affections, medicine has advanced wonderfully within the last half-century. Can we say as much in behalf of etiology? Putting aside communicable diseases, a reviewal of medical literature could leave no doubt as to the answer to this question. How many diseases have been loosely attributed to "taking cold," to physical habits of life, to mental conditions, to climate; and, when it has seemed irrational to specify causative agencies, it has been necessary to say that they originated spontaneously, overlooking the fact that spontaneity is no more applicable to pathological conditions than to any other of the phenomena of nature. It is a trite truism to say that all effects have adequate causes. To say that a 
disease has a spontaneous origin is no less a solecism than to regard a waterfall as fortuitous, taking no account of gravitation. Instead of saying that certain diseases arise spontaneously, a more honest expression is a simple confession of ignorance.

For several years there had been glimmerings of the light to be shed upon the causation of a large and important class of diseases which it is convenient to distinguish as infectious diseases. Indeed, long before the recent discoveries in bacterial etiology, it was apparent that the theory of the agency of living organisms afforded the only rational explanation of certain facts in the history of diseases now distinguished as infectious. Nearly fifty years ago, Sir Henry Holland, a philosophical writer, whose contributions to literature may be read to-day with pleasure and profit, advocated "the hypothesis of animalcule-life as a cause of disease." In 1847, James K. Mitchell, of Philadelphia, published a volume of much interest, in which were collected a host of facts in support of the cryptogamic origin of certain diseases. Other writers, in different countries, anticipated, on rational grounds, the demonstration of the correctness of the so-called germ-theory of the causation of diseases.

I assume it to be a demonstrated truth that 
the specific causes of certain of the infectious diseases are micro-organisms. I do not propose to inquire how many of these diseases have been known to be in this category or to discuss the evidence in regard to diseases which admit of doubt concerning the completeness of the demonstration. It is enough for my present purpose, that this truth has been demonstrated in but a single instance. The point which I wish to make is, assuming the truth of the parasitic origin of any one of the infectious diseases, that it is a logical inference that this truth is applicable to the other diseases of that class. If relapsing fever be shown to depend on a contagium vivum, small-pox and the other eruptive fevers have a similar dependence. If typhoid fever proceed from a specific microorganism, so does typhus fever. If yellow fever be parasitic, so is intermittent fever. Moreover, the discovery of a specific micro-organism as the cause of a disease, places it in the class of infectious diseases, although it had not previously been considdered as belonging in this class. Microscopical researches have thus lately enlarged this class of diseases, and the enlargement is likely to continue. Phthisis pulmonalis was regarded by few, if any, as an infectious disease prior to the discovery of the bacillus tuberculosis. If my reasoning be cor- 
rect, it is simply a question of time as to the discovery of specific organisms for all the infectious diseáses.

It is, to say the least, an innocent indulgence of the imagination to consider the influence of these discoveries upon medicine in the future. Having acquired knowledge of the natural history of the different species of parasitic organisms, a great practical object, of course, is to find means for their destruction within the body. Despite difficulties, this object will be accomplished. The parasiticides in cases of malarial fever were long ago discovered, although it is not certain that the parasite has yet been described. Here is a disease completely under control by remedies, the efficacy of which is to be explained by their destructive effect on a specific organism. Imagine all the infectious diseases to be as fully under control as are now the malarial affections! Is it an exaggeration to say that a revolution in medicine would then have taken place? This revolution will hereafter be dated from the recent discoveries in bacterial etiology.

It may be said that these discoveries do not warrant the glowing thoughts of the future which I have ventured to express, and that, up to the present time, they are barren as regards practical results. Granted difficulties never so great, when 
some of these are overcome, the way will be opened to overcome others more easily. To find an efficient and safe destructive agent for each species of pathogenic organisms, together with an effectual method in its employment, is not the only object to be kept in view in order to control infectious diseases. The presence of parasites is but one factor in the etiology of these diseases. Conditions favorable for the lodgment, growth, multiplication, and colonization of parasitic organisms--conditions which constitute a peculiar predisposition or diathesis-are not less essential. If these can be removed, the control will be as complete as if effected by parasiticides. Ground is as yet hardly broken in this field, and it is useless to speculate concerning the future products of its cultivation. It is not improbable that labors in this direction may be more speedily successful than efforts to discover toxical agents which destroy pathogenic organisms, leaving the patient unharmed.

To say that knowledge of bacterial etiology will lead to effective means for the arrest of infectious diseases is not perhaps to indicate the most important way in which this knowledge is to influence medicine in the future. The destruction of organisms outside of the body by disinfectants, and by the removal of all the accessory conditions 
necessary to their existence, together with their effectual exclusion from the body, may, and indeed it is more than probable will, reduce the fatality from infectious diseases, in the order of Providence, much sooner than the discovery of effective therapeutic agents. Moreover, there are present intimations of important discoveries respecting inoculation with attenuated viruses and contagia in order to forestall the development of infectious diseases. Here open up to the imagination the future triumphs of preventive medicine in respect to all classes of disease. The zeal and activity in this department of medicine often, in spite of obstacles arising from popular prejudice and indifference, redound to the glory of the medical profession.

Putting aside bacteriology, are there not pathological conditions, of which little or nothing is now known, which await important developments of knowledge in the future? The spleen must have functions liable to perversions, at present but little understood. Much remains to be learned respecting the hepatic functions, and we may look forward to the time when the term, biliousness, handed down from Hippocrates and Galen, shall have some definite meaning, and when the liver will no longer be available as a convenient source 
of ailments, the origin of which is confessedly unknown. Can it be doubted that the pathological conditions of the chylopoetic and the hæmatopoetic systems will in due season be elucidated, when will be found the missing link which binds together leucocythæmia, Hodgkins's disease, Addison's disease, and pernicious anæmia, and when new toxical agents in the blood will be brought to light? The glands of the stomach, it is estimated by Leube, secrete thirty pounds of gastric juice per diem, and the glands of Lieberkühn, an unknown but undoubtedly a very large quantity of intestinal juice; yet, lesions affecting these extensive glandular systems, and their functional disorders, are hardly recognized in the nosology. Here is a vast and fruitful field for future clinical researches. The thyroid body, the lymphatic glands, and the supra-renal capsules must have important physiological functions not yet ascertained, and a corresponding importance in pathology. When I think of the future discovery of pathological conditions, I connect my thoughts with the reflection, how great has been the influence of the researches of Bright on the doctrines and practice of medicine; and yet, within my own recollection, the relations of the kidneys to dropsy and uræmia were unknown. 
I should not do justice to my subject without offering some thoughts concerning medical literature; medical instruction, and the medical profession of the future.

With each successive decade in the last halfcentury, the medical press has been more and more prolific. The fecundity is likely to increase rather than diminish. There is no prospect of a menopause. What a progeny may be expected at the end of the next half-century! Consider the situation, at the present time, of that unfortunate person so often mentioned as the "busy practitioner"! $\mathrm{He}$ is naturally, as is to be hoped, anxious to be au courant with French, German, and English medical literature. With each successive month he consults the Index Medicus, "a monthly classified record of the current medical literature of the world." If he be thoroughly discouraged at this day, what must be the state of mind produced by consulting an Index Medicus in the year 1936? The truth is, that, at the present time, and still more in the future, the range of reading and study must be restricted, in a great measure, to limited parts of the vast field of medical literature.

The multiplicity of medical publications representing real advancement of knowledge in the several branches of medicine must lead to certain 
changes, some of which may be called reforms. Clinical studies will, of course, always hold a foremost place among the means of advancing knowledge of medicine; but there must be less superfluity of reported cases and less redundancy of details in published histories. A reform in these regards, as may be hoped, will extend to the tedious oral recitals of interesting cases, rendering tiresome the meetings of medical societies and sometimes marring the pleasure of social intercourse. The time may come when fewer books' will be written with a view to impress upon credulous readers the superior attainments and skill of their authors as practitioners in some special province of practice. It may be hoped, also, that future publications will abound much less in the profitless minutix of observations, experiments, and in tabulated data, representing often labor without valuable results. Another reform is the elimination of complicated schematic devices and ingeniously colored diagrams, laden with figures and embellished with curved lines. Future authors will be forced not to encumber books with a digest of all the past literature of the subjects treated of. The necessity for condensation and conciseness will become imperative. It is now truebut future readers will appreciate more fully the 
truth-that art is too long and life too short for busy practitioners to wade through bulky volumes or extended articles in order to ascertain whether or not they contain aught of value. It will be requisite that books shall contain a fair synopsis of their contents, so that judgment can be formed beforehand whether time will be wasted in a careful reading from cover to cover. Compendiums, analytical reviews, and the catalogue raisonne of libraries, of great use at all times, will be indispensable in the future. These and other contrivances must be resorted to for repressing and counteracting the exuberance of medical bibliography.

Voluminous encyclopedic works have probably had their day. It is doubtful if a French publisher will hereafter be bold enough to repeat an enterprise like that of the Nouvcau Dictionnaire de Mcidecine et de Chirurgie pratiques, which was begun in I 864 and, after the publication of thirty-eight octavo volumes, has but lately reached the end of the alphabet. The German work edited by Ziemssen, and entitled a Handbuch-a name which one might suspect to be a pleasantry, if the character of German writers laid them open to such a suspicion-a translation of which, more pretentiously called an "Encyclopædia of Practical Medicine," was published in America, in seventeen volumes, and is un- 
doubtedly a work of value. But, although several years have elapsed since the last volume was issued, the publishers probably have reason to congratu. late themselves that the work was sold by subscription.

There is reason for thinking that text-books which assume to extend over the whole domain of medicine will soon belong to the past. Owing to the progress in knowledge of diseases, and the developments in etiology, pathology, and therapeutics which this progress involves, it will soon require not a little hardihood for an author to undertake to furnish even a minimum of information that the medical student and the practitioner are expected to acquire of all or a considerable part of the diseases embraced in the nosology. Hereafter the department of medical literature embracing the principles and practice of medicine will consist of works limited to individual diseases or to nosological divisions. The accumulation within late years of the increasing number of treatises on diseases of the lungs, heart, nervous system, throat and nose, liver, stomach, bowels, kidneys and bladder, the diseases of children, the diseases peculiar to women, eruptive diseases, fevers, gout, etc., render it evident that such works must supersede those intended to cover the whole range of medical practice. 
Passing from medical literature to medical instruction, correlative changes in the latter are to be'expected. Fifty years ago, it was customary for a professor of medicine to write out in full lectures on pathology and practice (sometimes including physiology) which, with interlineations, were re-read year after year. To this custom the medical professor is indebted for the inimitable work of Watson. The custom now belongs to the past. The progress of medicine has made its continuance impracticable. More teaching and more teachers are indispensable. The amount of teaching and the number of teachers must continue to increase. The whole of general pathology can not longer be incorporated with practical medicine. Special branches require special teachers, and the number of special branches will multiply.

1 predict that didactic, except as complemental to clinical teaching, will be more and more restricted, and perhaps at length be discontinued, recitations and the study of books taking its place. Observation of the phenomena of disease, together with practical exercises in diagnosis and the applications of therapeutics to individual cases, are to the study of medicine what experimental illustrations are to the study of chemistry and physics; or, not going without the domain of medicine, they are 
what the use of the scalpel is in the study of anatomy, and the use of the microscope, in the study of histology. To point out and explain the pathological character and diagnostic import of morbid phenomena, as manifested in cases of disease under observation, to secure practical familiarity with methods of examination, and to demonstrate the results of practice-these are now, and will be still more in the future, the chief ends of oral instruction in medicine.

Bedside teaching and practical work in the histological laboratory will henceforth form an essential part of medical instruction. The medical student must not only learn what is already known of the practical applications of microscopy, but he may be incited thereby and qualified to extend the boundaries of knowledge in physiology and pathology. The study of the functions of the organs and tissues of the body in health and disease, of etiology, and of therapeutics, must include experiments on lower animals. It is a painful reflection that this study is hampered by penal restrictions in the most enlightened country on the globe. Yet this is not a solitary instance, within the last half-century, of obstruction to the progress of medicine by popular prejudice based on ignorance. It is not very long since the study of practical anatomy involved the 
necessity of either committing or being accessory to what the law of the land declared to be felony. The disśection of the human body, in the eyes of legislators, denoted a ghoul-like propensity developed by the study of medicine. The dissemination of popular knowledge has effaced this stigma in most civilized countries. So will it be in the future with what we may call experimental medicine. The profession in America look to the mother-country, as well as to France and Germany, for the active employment of all proper means for the advancement of medical knowledge. English jurisprudence, near the end of the nineteenth century, in an attitude of hostility to investigations inspired by humanity and having no motive or object save the welfare of mankind, is indeed a strange spectacle. As evidence of a prevailing popular sentiment of justice toward the medical profession, it is to be hoped that British novelists will ere long find more worthy objects for the exercise of the imagination than the portrayal of a vivisector as a person to be shunned or despised.

The medical profession of the future-this topic offers scope enough for thought, but my temerity is not sufficient for me to trespass except for a few moments on your further indulgence.

The ideal physician of the future, representing 
an advanced stage in the progress of medicine, will be, it is to be presumed, a better practitioner than the physician of our time. His practice will exemplify more knowledge of pathology and etiology, together with advancement in therapeutics and prophylaxis. We can fancy that, on appropriate occasions, at the end of the next half-century, he will review past medical history, and with complacency, as viewed from his standpoint, amplify on the defects and errors of the practitioners who represent the present stage of medical progress.

The progress of medicine induces, slowly but surely, changes in popular ideas. The physician of the future will, perhaps, not be better appreciated, but there will be a truer estimate of medical knowledge and of the medical profession. It is a pleasant thought that hereafter the practice of medicine may not be so closely interwoven as hitherto, in the popular mind, with the use of drugs. The time may come when the visits of the physician will not as a matter of course involve the co-operation of the pharmacist; when medical prescriptions will be divested of all mystery and have no force in the way of fortifying the confidence of the patient. The medical profession will have reached a high ideal position when the physician, guided by his knowledge of diagnosis, the natural history of diseases, 
and existing therapeutic resources, may, with neither self-distrust nor the distrust of others, treat an'acute disease by hygienic measures without potent medication. When this time comes, a system of practice which assumes to substitute medicinal dynamics for the vis medicatrix nature will have been added to the list of by-gone medical delusions.

But we must not look into the future exclusively in the light of optimism. Are there no prospective dangers incident to the progress of medicine? Let me briefly advert to one source of apprehension.

The unavoidable subdivision of medical literature and medical instruction into special departments makes necessary, to a certain extent, specialism in the practice of medicine. It is certain that this will not lessen, but increase, in the near future; and it is important to think of possible emergencies which are even now foreshadowed. Specialism conduces to the advancement of knowledge. It behooves us, however, to consider, were the practice of medicine to be given up to specialists, what would become of the medical profession. With due appreciation of services devoted to special branches of medical knowledge, there are tendencies pertaining to the practice of a specialty that should not be overlooked. I shall only 
allude to the danger of what may be called professional demoralization. I do not care to speak of those who adopt a specialty for other than the motives which have governed worthy physicians in all ages. A dangerous tendency is to such a limitation to a specialty as will lead to withdrawal from the common interests of the profession. A medical specialist should not thereby, in his sentiments and conduct, be any the less a physician; the honor, dignity, and usefulness of the profession, as a whole, should be as sacred in his estimation as if he were not a specialist. If the effect of specialism be otherwise, alas for the medical profession of the future, as regards the respect of others and the selfrespect of its members! For one, I can not believe that, in the order of Providence, the destiny of this profession is its degradation. The history of medicine has made the medical profession most honorable, and I believe that it has a glorious future.

Mr. President, I can not adequately express my appreciation of the honor of an invitation to read an address on medicine at a meeting of the British Medical Association. I am well aware that the invitation was intended, not as a personal compliment so much as a manifestation of good-will toward the medical profession of the United States, where the 
same language is spoken, a common literature enjoyed, and where the institutions, literary, educational, scientific, philanthropic, and political, are modeled largely after those of the parent country. On behalf of my American brethren I tender to yourself and to the members of the British Medical Association sincere thanks. The gratification with which the invitation was accepted would have been without any drawback could I have felt confident of my ability to do justice to the opportunity and the occasion. 








\section{University of California \\ SOUTHERN REGIONAL LIBRARY FACILITY \\ 305 De Neve Drive - Parking Lot 17 - Box 951388 \\ LOS ANGELES, CALIFORNIA 90095-1388}

Return this material to the library from which it was borrowed. 


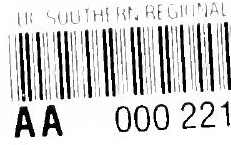


Unive

Sol

L 